\title{
Fenologia e sobrevivência de três populações de samambaias em remanescente de Floresta Atlântica Nordestina, Paraíba, Brasil
}

\author{
Rafael de Paiva Farias* \\ Sergio Romero da Silva Xavier \\ Departamento de Biologia, Centro de Ciências Sociais e Biológicas Aplicadas \\ Universidade Estadual da Paraíba \\ Rua Horácio Trajano, s/n, Cristo Redentor \\ CEP 58070-450, João Pessoa - PB, Brasil \\ *Autor para correspondência \\ rafaelpfarias@hotmail.com
}

Submetido em 30/11/2010

Aceito para publicação em 07/05/2011

\section{Resumo}

Visando contribuir para a conservação e o preenchimento da lacuna acerca do conhecimento ecológico das plantas vasculares sem sementes no Brasil, apresenta-se resultado da análise da fenologia e sobrevivência de três populações de samambaias (Acrostichum danaeifolium Langsd. \& Fisch., Lygodium volubile Sw. e Thelypteris serrata (Cav.) Alston) ocorrentes em remanescente de Floresta Atlântica no estado da Paraíba durante os períodos seco e chuvoso. Para tanto, dez indivíduos de cada população foram marcados e acompanhados em campo durante 12 meses, registrando dados fenológicos e de herbivoria, relacionando-os com dados climatológicos dos períodos. A taxa de sobrevivência e as causas mais comuns que ocasionaram as mortes dos indivíduos também foram registradas nesta amostra. Verificou-se que a produção de frondes estéreis nas populações estudadas teve ocorrência em ambas as estações sazonais, sendo esta significativamente maior durante o período chuvoso em L. volubile. Apenas A. danaeifolium produziu frondes férteis, não apresentando diferença significativa quanto à intensidade entre as estações. A senescência foliar ocorreu de forma contínua e não apresentou diferença significativa entre as estações nas populações de $A$. danaeifolium e $T$. serrata, diferentemente de $L$. volubile em que esta fenofase ocorreu apenas na estação chuvosa. As frondes de $A$. danaeifolium são atacadas continuamente por herbívoros, enquanto que em L. volubile às frondes são atacadas apenas na estação chuvosa. A menor exclusão amostral de indivíduos neste estudo ocorreu para A. danaeifolium (20\%), sendo a maior registrada para T. serrata (40\%). O ressecamento e os acidentes naturais são as principais causas que ocasionaram as mortes dos indivíduos neste estudo (cerca de 90\%).

Palavras-chave: Acrostichum danaeifolium, Frondes, Lygodium volubile, Senescência, Thelypteris serrata

\section{Abstract}

Phenology and survival of three populations of ferns in fragment of Atlantic Forest, in Paraíba, Brazil. With the goal of contributing to the conservation, and knowledge about the ecology, of seedless vascular plants in Brazil, the present study describes the results of an analysis of the phenology and survival rates of three populations of ferns (Acrostichum danaeifolium Langsd. \& Fisch., Lygodium volubile Sw. and Thelypteris serrata (Cav.) Alston). The study was conducted in a fragment of the Atlantic Forest, in the state of Paraíba, during 
the dry and rainy seasons. Ten individuals from each population were tagged, and observed in the field over a 12-month period. Data about phenology and herbivory were recorded and related to seasonal climatological data. Survival rates and the most common causes of death were also recorded. The production of sterile fronds occurred during both seasons. Significantly greater production of these leaves was observed in L. volubile during the rainy season. Only $A$. danaeifolium produced fertile fronds with no significant difference between seasons. Foliar senescence continuously occurred with no significant seasonal differences in A. danaeifolium and T. serrata, whereas this phenophase only occurred in the rainy season in L. volubile. The fronds of A. danaeifolium were continuously attacked by herbivores, whereas those of $L$. volubile were only attacked during the rainy season. The lowest rate of death of the individuals studied occurred in A. danaeifolium (20\%), whereas the highest rate occurred in $T$. serrata $(40 \%)$. Desiccation and natural accidents were the main causes of death among the individuals (approximately 90\%).

Key words: Acrostrichum danaeifolium, Fronds, Lygodium volubile, Senescence, Thelypteris serrata

\section{Introdução}

A fenologia que compreende o estudo das variações fenotípicas in situ e das causas de sua ocorrência ao longo de ciclos sazonais foi pouco evidenciada para a maioria absoluta das samambaias e licófitas ocorrentes no Brasil, destacando-se os trabalhos de Dias-Filha (1989), Ranal (1995), Souza et al. (2007), e as obras de Lehn et al. (2002), Franz e Schmitt (2005), Schmitt e Windisch (2005; 2007), Miranda (2006; 2008), Lehn (2008), Silva (2008), Souza (2009), Schmitt et al. (2009) que também denotaram aspectos relacionados ao desenvolvimento de espécies deste grupo vegetal.

Cosmopolitas, as samambaias e licófitas são parte integrante da flora mundial que frequentemente associase ao sub-bosque florestal, mas também estão presentes em terras áridas ou em superfícies recém-expostas, tais como, áreas pós-deslizamentos, queimadas e clareiras, crescendo também em cursos aquáticos e áreas de pastagens (MEHLTRETER et al., 2010).

Apesar desta diversificação adaptativa, as samambaias e licófitas apresentam-se altamente dependentes da disponibilidade hídrica do ambiente, fator este determinante aos aspectos reprodutivos, como a realização da fecundação (COELHO et al., 2007), determinando também o estabelecimento, a periodicidade de crescimento e a dormência destas plantas em ambientes sazonalmente secos, como destacado por Kornás (1977). Assim, estudos fenológicos em clima marcadamente sazonal explicitando a resposta destas plantas aos fatores abióticos (temperatura e precipitação pluviométrica), possibilitam a avaliação do desenvolvimento populacional das espécies em determinado intervalo de tempo, fornecendo informações imprescindíveis para serem utilizadas em programas de uso e conservação das espécies, bem como para seus respectivos hábitats.

Neste contexto, o presente estudo visa contribuir para a conservação e o preenchimento da lacuna acerca do conhecimento ecológico das plantas vasculares sem sementes no Brasil, analisando a fenologia e sobrevivência de três populações ocorrentes em remanescente de Floresta Atlântica nordestina durante os períodos seco e chuvoso.

Especificamente, buscou-se responder às seguintes questões: qual (ais) período (s) de ocorrência dos eventos fenológicos e da herbivoria foliar, e se existem diferenças numéricas significativas destes entre as estações climáticas, bem como determinar a taxa de exclusão amostral em cada população, e quais as causas mais comuns que ocasionaram as mortes dos indivíduos.

\section{Material e Métodos}

\section{Área de estudo}

O Jardim Botânico Benjamim Maranhão (Mata do Buraquinho) (7॰08'46,25”S e $\left.34^{\circ} 51^{\prime} 39,90^{\prime \prime} \mathrm{W}\right)$ compreende uma área de 343 ha, e está localizado no perímetro urbano do município de João Pessoa, Paraíba. A área possui uma altitude média de $45 \mathrm{~m}$, apresentando um solo predominantemente pobre, constituído por sedimentos areno-argilosos, pouco consolidados do grupo Barreiras, formando em algumas 
áreas, verdadeiros bolsões de areia que apresentam uma vegetação fisionomicamente diferente, regionalmente conhecida como tabuleiro costeiro (BARBOSA, 1996).

De acordo com Macedo et al. (2010) ao analisar a série histórica em relação à precipitação pluviométrica do estado da Paraíba, verifica-se que o município de João Pessoa encontra-se numa subdivisão, onde a precipitação média anual é de $1177,3 \mathrm{~mm}$, com quadrimestre mais chuvoso entre abril e julho.

\section{Traballho de campo}

Durante o período de setembro/2008 a agosto/2009, foram realizadas excursões mensais para o monitoramento do desenvolvimento de três populações da pteridoflora local, Acrostichum danaeifolium Langsd. \& Fisch., Lygodium volubile Sw. e Thelypteris serrata (Cav.) Alston. Estas espécies possuem ampla distribuição geográfica, sendo $A$. danaeifolium encontrada na América, Ásia, África e/ou Oceania, enquanto $L$. volubile e $T$. serrata ocorrem na América do sul, América Central e eventualmente na América do Norte (PEREIRA et al., 2011). As espécies estudadas foram escolhidas por serem as populações de samambaias mais representativas em relação a número de indivíduos na área estudada, de modo que entender seus aspectos fenológicos possibilita conhecer como estas interagem com o ambiente obtendo sucesso, gerando informações úteis para programas de manejo.

Para o estudo das populações de Acrostichum danaeifolium e Thelypteris serrata, por conta da baixa ocorrência de indivíduos nesta área, foram marcados dez indivíduos com fitas personalizadas, de diferentes estágios de vida, distribuídos em dois pontos distantes entre si (100m em valores aproximados) que compreendiam as únicas áreas de ocorrência destas espécies durante a marcação dos indivíduos no período inicial do estudo. Ambos os pontos se caracterizavam pela ausência de dossel tamponante, proximidade a um córrego, e na borda do remanescente. Entretanto também se faz necessário relatar que apesar de não quantificada, se observou umidade no solo apenas durante a estação chuvosa. Em Lygodium volubile, foram marcados dez indivíduos jovens com apenas um par de pinas, em três pontos distantes entre si (mínimo de 50m e máximo de $100 \mathrm{~m}$ em valores aproximados) ao longo da trilha florestal, utilizandose fitas personalizadas, destacando que três destes indivíduos localizavam-se na encosta de uma declividade. Considera-se que o número de indivíduos selecionados para as observações destas espécies é representativo, pelo fato do reduzido número de indivíduos encontrados na área. Esta sendo a realidade de alguns remanescentes de Floresta Atlântica nordestina que sofreu grande redução, principalmente quando inseridos em um contexto urbano. A opção por estudar a espécie $L$. volubile no estágio de vida jovem ocorreu devido à mesma apresentar hábito escandente e crescimento indeterminado, características que dificultariam a obtenção dos dados em caso de indivíduos adultos. Neste estudo, os indivíduos foram diferenciados durante o período inicial da demarcação, em que quando se encontravam próximos nos mesmos pontos de ocorrência seus respectivos rizomas foram parcialmente desenterrados. Sendo a população compreendida como o número de indivíduos na área estudada que apresentavam rizomas independentes.

Entendemos que a baixa ocorrência de indivíduos na pteridoflora local não pode constituir uma dificuldade na realização de estudos desta natureza, devendo representar um incremento, já que através destes se conhecem o desenvolvimento das populações em ciclos sazonais, reconhecendo possíveis mecanismos que ocasionam o declínio destas populações na área.

Em cada população, foram quantificados e registrados dados referentes ao número de báculos, de frondes estéreis e férteis, frondes senescentes, frondes predadas, além do número de indivíduos exclusos da amostra (Classe I: morte por ressecamento ou acidentes naturais; Classe II: outros motivos) que seguiu critérios e métodos estabelecidos por Ranal (1995).

\section{Análises dos dados}

Para confirmar diferenças da pluviosidade durante os períodos seco e chuvoso foi utilizado o teste $-t$, com dados de precipitação pluviométrica. Também mediante ao teste $-t$ foi realizada uma comparação do número de báculos, frondes estéreis e férteis, senescentes e predadas em cada uma das estações para verificar se existem 
diferenças numéricas significativas entre estes períodos. As análises estatísticas dos dados foram realizadas através do software Bioestat 5.0 (AYRES et al., 2007).

Os dados fenológicos foram analisados segundo a média e percentual, relacionado-os com os dados climatológicos (temperatura e precipitação pluviométrica) obtidos ao longo do ano através do Instituto Nacional de Meteorologia - INMET (Figura 1) (INMET, 2009).

\section{Resultados e Discussão}

Ao verificar dados de pluviosidade em relação a períodos seco e chuvoso conforme o clima local se confirmou um padrão de sazonalidade (Figura 2).

A emergência de frondes estéreis evidenciada pela presença de báculos não foi observada para a população de Lygodium volubile, enquanto que para Acrostichum danaeifolium (média mensal de cerca de 5,0 báculos) e Thelypteris serrata (média mensal de cerca de 2,0 báculos) esta ocorreu ao longo de todo período estudado (Figura 3), apresentando diferenças significativas em relação à intensidade entre os períodos seco e chuvoso. Na população de $A$. danaeifolium a produção de báculos foi significativamente maior durante o período chuvoso, fato este não observado para a população de T. serrata, que apresentou maior produção de báculos durante a estação seca, sendo importante destacar que a maior

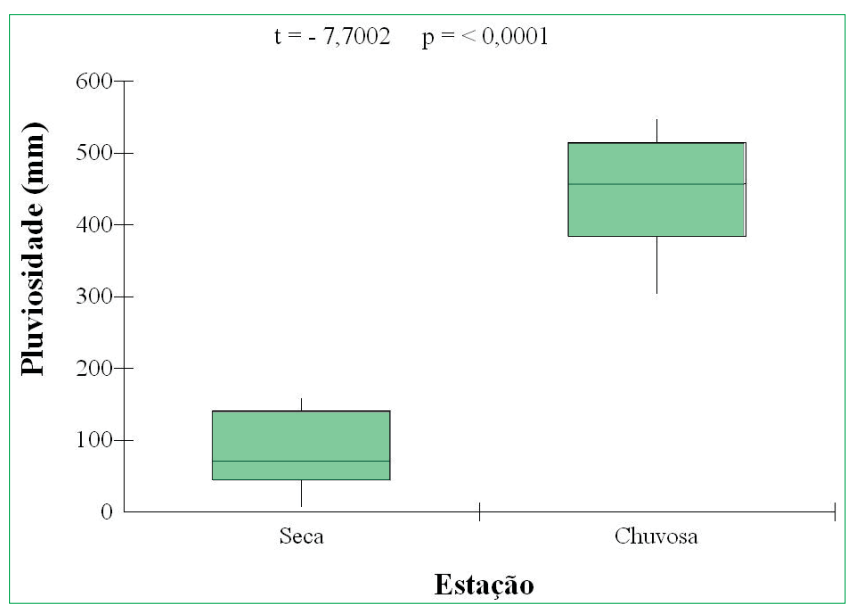

FIGURA 2: Teste $\mathrm{t}$ realizado com os dados de pluviosidade do município de João Pessoa, Paraíba, Brasil, relativo ao período estudado, analisando o padrão de sazonalidade.

exclusão de indivíduos em $T$. serrata contribuiu para o decréscimo na produção de báculos durante o período com alta disponibilidade hídrica. Tais resultados diferem das observações durante um ano de Souza et al. (2007) ao verificarem uma produção de báculos apenas na estação chuvosa em Anemia tomentosa var. anthriscifolia (Schrad.) Mickel numa Floresta Semidecídua do estado de Pernambuco. Entretanto, a ocorrência desta fenofase em A. danaeifolium e T. serrata demonstrou similaridade com as observações realizadas durante um ano por Silva (2008) ao observar uma produção contínua de báculos em 10 indivíduos de Cyathea corcovadensis (Raddi) Domin,

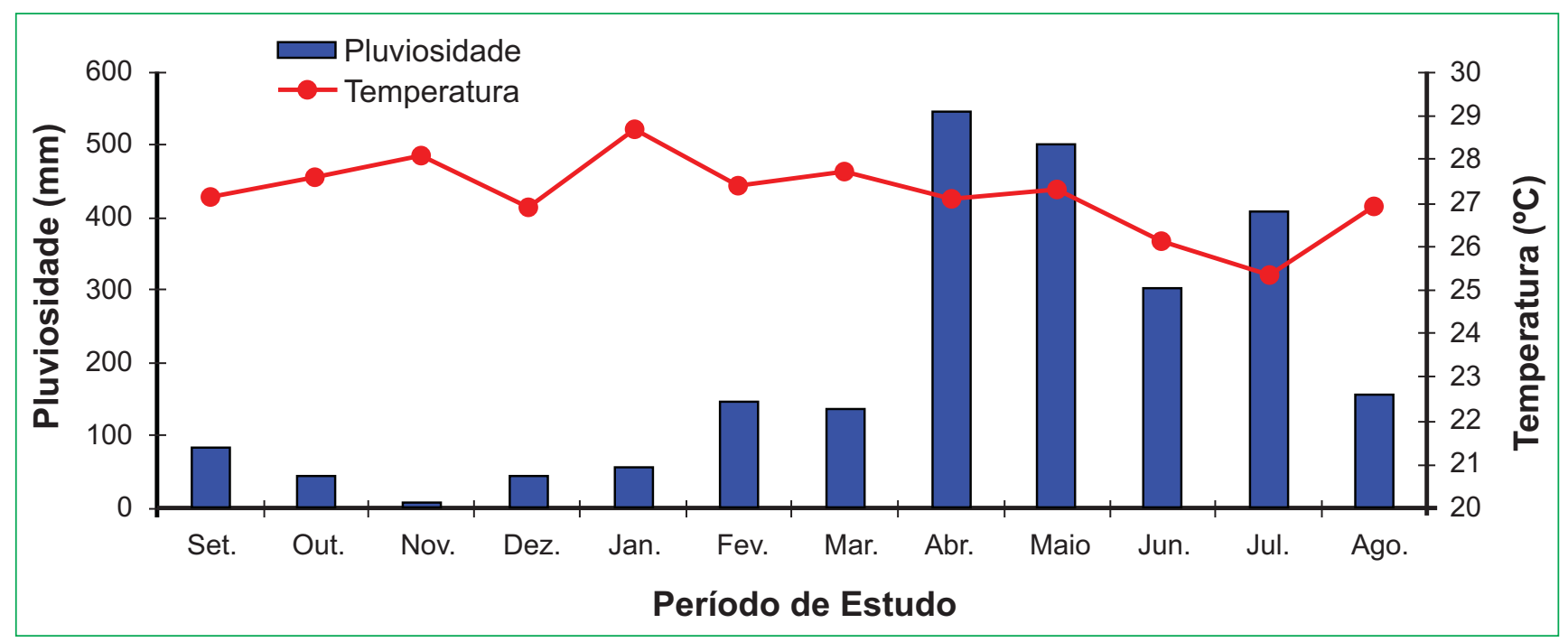

FIGURA 1: Dados pluviométricos e temperatura média registrada durante o período de Setembro (2008) a Agosto (2009) para o município de João Pessoa, Paraíba, Brasil. 

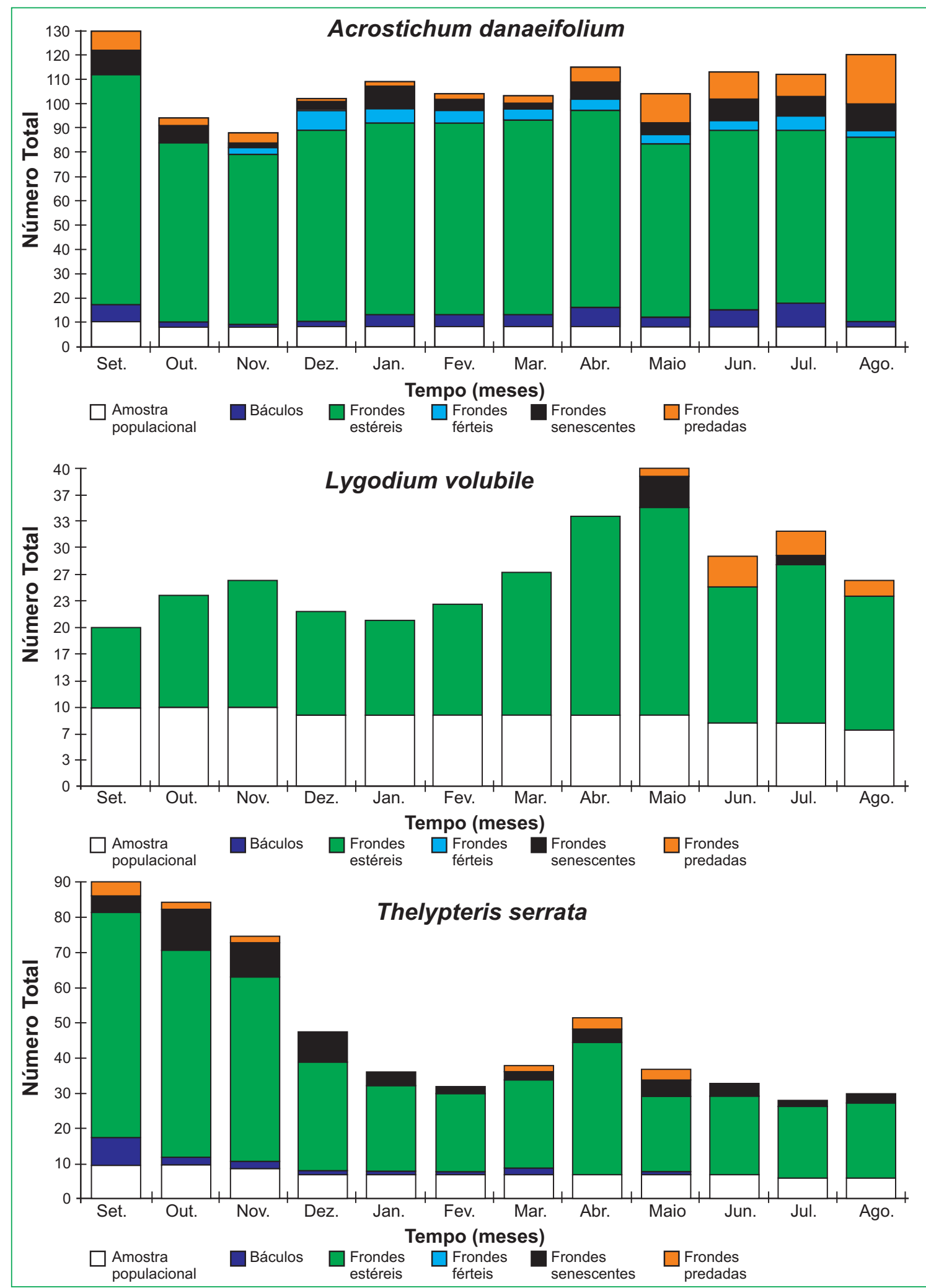

FIGURA 3: Amostra populacional, número total de báculos e frondes registrados para as populações de Acrostichum danaeifolium Langsd. \& Fisch., Lygodium volubile Sw. e Thelypteris serrata (Cav.) Alston, durante o período estudado, município de João Pessoa, Paraíba, Brasil. 
C. microdonta (Desv.) Domin, e C. praecincta (Kunze) Domin, que apesar de arborescentes, estão também inseridas num hábitat de Floresta Atlântica nordestina.

A produção de frondes estéreis nas populações estudadas teve ocorrência em ambas às estações sazonais (Figura 3). As médias mensais de frondes estéreis para as populações de Acrostichum danaeifolium (cerca de 76 frondes estéreis) e Thelypteris serrata (cerca de 35 frondes estéreis) não apresentaram diferenças significativas entre os períodos seco e chuvoso. No entanto, destaca-se que as exclusões de indivíduos, desta vez associado à senescência foliar nestas populações ocasionaram um decréscimo nesta fenofase durante o período com maior disponibilidade hídrica, principalmente em $T$. serrata (Figura 3). Este padrão de produção de folhas estéreis, observado nas populações de $A$. danaeifolium e $T$. serrata, diferiu do observado no estudo de Mehltreter e PalaciosRios (2003) em área de manguezal no México para $A$. danaeifolium, que demonstrou uma produção foliar significativamente maior durante o período chuvoso. No entanto, apresentou similaridade ao registrado no estudo anual de Souza (2009) que indicou uma produção foliar independente da pluviosidade para 13 indivíduos de Adiantum pulverulentum L. na Floresta Semidecídua do estado de Pernambuco. Diferentemente, verificou-se um aumento significativo no período chuvoso quanto à produção foliar para a população de Lygodium volubile que apresentou média mensal de cerca de 17 frondes estéreis. Uma produção de folhas estéreis em ambas às estações climáticas e significativamente maior no período chuvoso também foi registrado para Lygodium venustum Sw. no México (MEHLTRETER, 2006). Indicando que ocorre um estímulo a esta fenofase nestas espécies em função direta da precipitação pluviométrica, padrão este também observado nas informações obtidas por Ranal (1995) ao estudar a fenologia populacional de oito espécies de samambaias em Floresta Semidecídua do estado de São Paulo, e por Dias-Filha (1989) ao estudar aspectos fenológicos da referida espécie na Floresta Atlântica do estado de Pernambuco.

Das populações estudadas, apenas a de Acrostichum danaeifolium apresentou frondes férteis (Figura 3), destacando que esta ocorrência se deu durante o período chuvoso e seco (média mensal de cerca de 5,0 frondes férteis), e não demonstrou diferença em relação à intensidade, diferenciando-se dos estudos de Mehltreter e Palacios-Rios (2003) em uma área de Manguezal no México para esta mesma espécie, ao relatar um padrão fortemente correlacionado com as mudanças sazonais. Tal padrão provavelmente decorre das condições ecológicas particulares da área estudada, que diferentemente do local do presente estudo, a região do manguezal invariavelmente encontra-se em áreas de limite com a restinga, caracterizadas por altas temperaturas e solos bastante salinos. Assim, evidencia-se a eficiente estratégia adotada pela população de $A$. danaeifolium estudada, que apesar de apresentar um maior gasto energético pela produção contínua de esporos, garante que estes sejam liberados em algum período ideal para seu desenvolvimento. A não ocorrência de frondes férteis em indivíduos jovens de Lygodium volubile indica que exista um período necessário à maturidade das folhas. Característica esta que reforça o posicionamento de Ranal (1995) a qual observou que as primeiras folhas formadas em geral são estéreis e somente a partir da estação chuvosa do ano seguinte ocorre o início da produção de folhas férteis. Neste contexto, Mehltreter (2006) ao estudar a fenologia foliar de L. venustum $\mathrm{Sw}$. e não relatar a existência de frondes férteis em sua amostra supõe que a direta incidência solar seja fator primordial para a indução de fertilidade nestas plantas. Em vista disso, é provável que seja necessário um período de crescimento dos indivíduos desta população, concomitante com o processo de maturação foliar como destacado anteriormente. A não ocorrência desta fenofase em Thelypteris serrata talvez seja decorrente de evento reprodutivo supra-anual, assim como em L. volubile.

A senescência foliar ocorreu ao longo de todo período estudado nas populações de Acrostichum danaeifolium (média mensal de cerca de 7,0 frondes senescentes) e Thelypteris serrata (média mensal de cerca de 5,0 frondes senescentes) (Figura 3), não apresentando diferenças significativas quanto à intensidade entre os períodos seco e chuvoso. A ocorrência de frondes senescentes na população de $A$. danaeifolium e $T$. serrata durante todo período estudado pode estar relacionada à ausência de um dossel tamponante, ocasionando uma exposição às elevadas temperaturas, possivelmente associada à ação das chuvas sobre os indivíduos durante a estação chuvosa. A maior ocorrência desta fenofase em $A$. danaeifolium durante o período estudado deve ser decorrente do modo de fertilidade registrado para a referida espécie, 
apresentando pinas férteis por toda fronde que rapidamente são submetidas ao processo de senescência. Em Lygodium volubile, registrou-se uma baixa senescência foliar (cinco frondes), esta ocorrente apenas no período chuvoso (Figura 3). Tais resultados diferem das observações de Chiou et al. (2001) ao relatar a relação da senescência com o verão para Cibotium taiwanense C. M. Kuo em uma Floresta do Norte de Taiwan, bem como as de Franz e Schmitt (2005) que indicaram os períodos desfavoráveis, tal como aqueles com baixa pluviosidade, com uma significativa maior ocorrência de frondes senescentes em Blechnum brasiliense Desv. numa Floresta Estacional Semidecidual no estado do Rio Grande do Sul. Ainda sobre L. volubile, a baixa senescência foliar registrada pode estar relacionada ao estágio de vida da população, que por ser bastante jovem não apresenta frondes senescentes inicialmente, observando-se os primeiros registros desta fenofase após oito meses, demonstrando assim a resistência de suas frondes jovens ao processo de senescência. Destacamos ainda que o menor número de frondes senescentes em relação às frondes estéreis, evidenciado ao longo deste estudo nas três populações, demonstra que apesar das diferentes condições em relação à precipitação pluviométrica, as populações mantêm o número de frondes estéreis em nível estável. Tal equilíbrio também foi registrado por Miranda (2008) nas populações de Blechnum brasiliense e $B$. occidentale L.

A herbivoria foliar verificada neste período de estudo indicou que as frondes de Acrostichum danaeifolium são atacadas continuamente (média mensal de cerca de 7,0 frondes predadas) (Figura 3), não se observando uma diferença significativa em relação à intensidade deste processo entre as estações sazonais. A herbivoria nesta população atingiu máximo de $26,31 \%$ frondes predadas em relação ao total durante o mês de agosto. Em Lygodium volubile registrou-se que às frondes não são atacadas por herbívoros durante a estação seca, sendo a estação chuvosa o período preferencial a ação herbívora (média mensal de cerca de 2,0 frondes predadas) (Figura 3), atingindo máximo de 23,52\% frondes predadas em relação ao total durante o mês de junho. Para Thelypteris serrata a herbivoria foliar demonstrou oscilações (média mensal de cerca de 3,0 frondes predadas), não demonstrando diferença quanto à intensidade durante o período seco e chuvoso, e atingindo pico de 13,63\% frondes predadas em relação ao total durante o mês de maio, período que compreende a estação chuvosa (Figura 3). A relação da herbivoria com a pluviosidade, visualizada na população de $L$. volubile, difere do padrão observado por Lehn (2008) ao demonstrar que às taxas de herbivoria em Danaea sellowiana $\mathrm{C}$. Presl não apresentaram correlação com as variações sazonais nos níveis de pluviosidade. Por outro lado, o resultado deste trabalho se assemelha ao padrão da herbivoria registrado em $A$. danaeifolium e T. serrata.

Dados relativos à exclusão amostral demonstraram que $20 \%$ dos indivíduos de $A$. danaeifolium foram exclusos (menor exclusão amostral deste estudo) (Figura 3), ocorrendo apenas na estação seca e dentro da classe de exclusão tipo I (especificamente pelo ressecamento irreversível). Em Lygodium volubile a exclusão amostral atingiu 30\% dos indivíduos (dois ocorrentes na encosta da declividade) (Figura 3), sendo 10\% ocorrente na estação seca e $20 \%$ durante a estação chuvosa, destacandose ainda que $20 \%$ destas ocorreram dentro da classe de exclusão tipo I (especificamente pela remoção do esporófito por ação das chuvas) e $10 \%$ da classe tipo II. Para Thelypteris serrata registrou-se a maior exclusão amostral deste estudo, equivalente a $40 \%$ dos indivíduos (Figura 3), sendo 30\% ocorrente durante a estação seca e $10 \%$ na estação chuvosa, todas estas relacionadas à classe de exclusão tipo I (especificamente pelo ressecamento irreversível). Diante destes resultados verifica-se uma vulnerabilidade das populações de samambaias estudadas em relação à variação das condições ambientais, principalmente no contexto de seus micro-hábitats na trilha florestal e borda do remanescente com ausência de dossel tamponante que não possibilitam uma estabilidade ambiental. Diante das taxas de exclusão amostral, notase que o ressecamento e os acidentes naturais (exclusão amostral tipo I) são as principais causas que ocasionaram às mortes dos indivíduos neste estudo (cerca de 90\%). Demonstrando similaridade com o estudo de Ranal(1995) ao registrar que a maioria das mortes em gametófitos e esporófitos das oito espécies estudadas ocorreu por ressecamento irreversível seguido dos acidentes naturais.

Mediante as observações realizadas no presente estudo, evidencia-se a ocorrência de eventos fenológicos relacionados aos fatores climáticos, e outros não relacionados, numa mesma espécie, apesar do clima ser marcadamente sazonal. Indicando assim que a sazonalidade não é característica para a ocorrência 
de todas as fenofases em Acrostichum danaeifolium, Lygodium volubile e Thelypteris serrata. Esta assincronia nas fenofases ocorre talvez pelo fato destas espécies serem comuns na pteridoflora nordestina e frequentemente associadas a hábitats perturbados, favorecendo um processo adaptativo a hábitats com diferentes regimes de pluviosidade e temperatura. Destaca-se também que além da influência dos fatores climáticos analisados, as condições de micro-hábitat (ausência de dossel tamponante, borda florestal, encosta de declive) se mostram determinantes para o desenvolvimento das populações estudadas. Fato que corrobora para a importância da conservação do ecossistema estudado, visando à manutenção de microhábitats que proporcionem o desenvolvimento e o sucesso reprodutivo das samambaias ocorrentes no local.

\section{Referências}

AYRES, M.; AYRES JR, M.; AYRES, D. L.; SANTOS, A. S. BioEstat 5.0 - Aplicações estatísticas nas áreas das Ciências Biológicas e Médicas. 5. ed. Belém: Sociedade Civil Mamirauá, 2007. 290 p.

BARBOSA, M. R. V. Estudo florístico e fitosociológico da Mata do Buraquinho, João Pessoa, Paraíba. 1996. 135 f. Tese (Doutorado em Biologia Vegetal) - Universidade Estadual de Campinas, Campinas. 1996.

CHIOU, W. L.; LIN, J. C.; WANG, J. Y. Phenology of Cibotium taiwanense (Dicksoniaceae). Taiwan Journal of Botany, Taipei, v. 16, n. 4, p. 209-215, 2001.

COELHO, S. J.; CARVALHO, E. M. A. F.; MAIA, L. G. S. Resgate das Pteridófitas na área diretamente afetada do Aproveitamento Hidrelétrico do Funil - MG. Revista Brasileira de Biociências, Porto Alegre, v. 5, n. 1, p. 489-491, 2007.

DIAS-FILHA, M. C. C. Aspectos fenológicos e germinação dos esporos de Lygodium volubile Sw. (Schizaeaceae). 1989. $124 \mathrm{f}$. Dissertação (Mestrado em Criptógamos) - Universidade Federal de Pernambuco, Recife. 1989.

FRANZ, I.; SCHMITT, J. L. Blechnum brasiliense Desv. (Pteridophyta, Blechnaceae): estrutura populacional e desenvolvimento da fase esporofítica. Pesquisas Botânica, São Leopoldo, v. 56, p. 173-184, 2005.

INMET - Instituto Nacional de Meteorologia. 2009. Disponível em <http://www.inmet.gov.br/sim/sonabra/convencionais.php>. Acesso em: 16 setembro 2009.

KORNÁS, J. Life-forms and seasonal patterns in the pteridophytes in Zambia. Acta Societatis Botanicorum Poloniae, Bratislava, v. 46, p. 669-690, 1977.

LEHN, C. R. Aspectos estruturais e fenológicos de uma população de Danaea sellowiana C. Presl. (Marattiaceae) em uma Floresta Estacional Semidecidual no Brasil Central. 2008. 90 f. Dissertação (Mestrado em Biologia Vegetal) - Universidade Federal de Mato Grosso do Sul, Campo Grande. 2008.
LEHN, C. R.; SCHMITT, J. L.; WINDISCH, P. G. Aspectos do desenvolvimento vegetativo de Rumohra adiantiformis (Forst.) Ching (Pteridophyta/Dryopteridaceae), em condições naturais. Revista Estadual, Novo Hamburgo, v. 25, n. 2, p. 21-28, 2002.

MACEDO, M. J. H.; GUEDES, R. V. S.; SOUSA, F. A. S.; DANTAS, F. R. C. Análise do índice padronizado de precipitação para o estado da Paraíba, Brasil. Revista Ambiente \& Água - An Interdisciplinary Journal of Applied Science, Taubaté, v. 5, n. 1, p. 204-214, 2010.

MEHLTRETER, K. Leaf phenology of climbing fern Lygodium venustum in Semideciduous Lowland Forest on the Gulf of México. American Fern Journal, New York, v. 96, n. 1, p. 21-30, 2006.

MEHLTRETER, K.; PALACIOS-RIOS, M. Phenological Studies of Acrostichum danaeifolium (Pteridaceae, Pteridophyta) at mangrove site on the Gulf of México, Journal of Tropical Ecology, Winchelsea, v. 19, p. 155-162, 2003.

MEHLTRETER, K.; WALKER, L. R.; SHARPe, J. M. Fern Ecology. Cambridge: Cambridge University Press, 2010. 429 p.

MIRANDA, A. M. Estudo fenológico de Cyclodium meniscioides (Willd.) C. Presl (Dryopteridaceae - Monilophyta) na Mata da Piedade, Usina São José (Igarassu, Pernambuco - Brasil). 2006. 31 f. Monografia (Curso de Ciências Biológicas) - Universidade Federal de Pernambuco, Recife. 2006.

MIRANDA, A. M. Fenologia de duas espécies de pteridófitas (Blechnaceae - Monilophyta) na Floresta Atlântica Nordestina. 2008. 58 f. Dissertação (Mestrado em Biologia Vegetal) Universidade Federal de Pernambuco, Recife. 2008.

PEREIRA, A. F. N.; BARROS, I. C. L.; SANTIAGO, A. C. P.; SILVA, I. A. A. Florística e distribuição geográfica das samambaias e licófitas da Reserva Ecológica de Gurjaú, Pernambuco, Brasil. Rodriguésia, Rio de Janeiro, v. 62, n. 1, p. 1-10, 2011.

RANAL, M. A. Estabelecimento de pteridófitas em Mata Mesófila Semidecídua do estado de São Paulo. 3. Fenologia e sobrevivência dos indivíduos. Revista Brasileira de Biologia, São Carlos, v. 55, n. 4, p. 777-787, 1995.

SCHMITT, J. L.; SCHNEIDER, P. H.; WINDISCH, P. G. Crescimento do cáudice e fenologia de Dicksonia sellowiana Hook. (Dicksoniacae) no sul do Brasil. Acta Botânica Brasilica, Feira de Santana, v. 23, n. 1, p. 282-291, 2009.

SCHMITT, J. L.; WINDISCH, P. G. Aspectos ecológicos de Alsophila setosa Kaulf. (Cyatheaceae, Pteridophyta) no Rio Grande do Sul, Brasil. Acta Botânica Brasilica, Feira de Santana, v. 19, n. 4, p. 859-865, 2005.

SCHMITT, J. L.; WINDISCH, P. G. Aspectos ecológicos da produção de frondes em Cyathea delgadii (Cyatheaceae) no Rio Grande do Sul. Acta Botânica Brasilica, Feira de Santana, v. 21, n. 3, p. 731-740, 2007.

SILVA, F. C. L. Ecofisiologia de Cyatheaceae (Monilophyta): Fenologia, banco de esporos, anatomia e germinação. 2008. 91 f. Tese (Doutorado em Biologia Vegetal) - Universidade Federal de Pernambuco, Recife. 2008.

SOUZA, K. R. S. Fenologia populacional de três espécies de Monilophyta em fragmento de Floresta Semidecídua, Pernambuco, Brasil. 2009. 60 f. Dissertação (Mestrado em Botânica) - Universidade Federal Rural de Pernambuco, Recife. 2009.

SOUZA, K. R. S.; ALVES, G. D.; BARROS, I. C. L. Fenologia de Anemia tomentosa (Sav.) Sw. var. anthriscifolia (Schrad.) Mickel em fragmento de Floresta Semidecídua, Nazaré da Mata, Pernambuco, Brasil. Revista Brasileira de Biociências, Porto Alegre, v. 5, supl. 2, p. 486-488, 2007. 